\section{A simple capacitive discharge welder for neurophysiological implant surgery*}

\author{
STEPHEN WALKER and MARTIN REITE† \\ Department of Psychiatry \\ University of Colorado Medical Center \\ 4200 East. Vinth Avenue, Demer, Colorado 80220
}

Stainless steel is useful in a variety of physiological and neurophysiological applications. Depth and surface EEG electrodes are frequently made from it, and multistranded Teflon-coated stainless steel wire is excellent for long subcutaneous leads where stress fatigue must be avoided. Unfortunately, stainless steel is notoriously difficult to solder, and unprotected solder joints may produce adverse tissue reactions. Electric welding is ideal where stainless steel must be electrically and mechanically joined in the body. As commercially available welders are usually more elaborate and expensive than necessary for most neurophysiological applications, we have developed the simple and inexpensive capacitive discharge welder described below, and have found it most useful in neurophysiological applications.

The welder consists of a large $(80,000 \mu \mathrm{F})$ electrolytic capacitor for storage of the welding charge, a variable power supply for charging the capacitor, a footpedal switch, and welding tweezers. The circuit diagram is shown in Fig. 1.

Any dc power supply with a variable output voltage of up to $18 \mathrm{~V}$ may be used. A voltmeter is incorporated into the circuit to permit control of the charge on the capacitor. Final charge values of $10-18 \mathrm{~V}$ are generally adequate for welding thin wires (e.g., 0.012 in.), tubing (up to $20 \mathrm{ga}$ ), etc. It is possible to use three $6 \cdot \mathrm{V}$ automobile batteries in series (or a 12- and 6-V) for the power supply if a simple voltage divider and voltmeter is incorporated into the circuit so that the charging voltage can be controlled. With batteries, a switch should be incorporated in the circuit to disconnect the battery once the capacitor is charged and so prevent the batteries' continued discharge through the voltage divider circuit.

The foot pedal is normally up, in which case $R$ and the internal power supply resistance limits the current flowing to charge the capacitor. The initial current charging the capacitor is found from

$$
I=\frac{E}{R},
$$

where $\mathrm{I}$ is the initial charging current, $\mathrm{E}$ is the power supply voltage, and $\mathrm{R}$ is the sum of the internal

*This project was supported by National Institute of Mental Health Research Grant MH-19514.

†Supported by NIMH Research Scientist Development Award. Type 1, No. 5-KO-1-MH-46335.

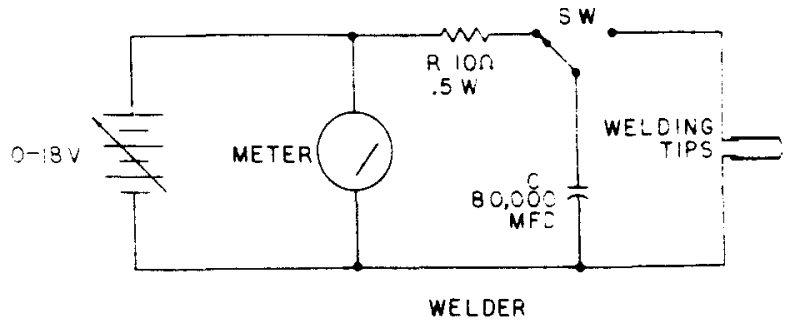

Fig. 1. An example of the simple capacitative discharge welder.

resistance of the power supply and the external resistor, $\mathrm{R}$. This initial current can be quite large, and with certain batteries or power supplies, it might have to be limited by increasing the value of the resistor, $\mathrm{R}$, using Formula 1 .

When the foot pedal is depressed, the switch breaks the connection to the power supply and discharges the capacitor through the welder tweezers. Releasing the foot pedal causes the capacitor to be recharged with a time constant (TC) of several seconds. The recharge time constant is found from

$$
\mathrm{TC}=\mathrm{RC},
$$

where $R$ is the sum of the power supply internal resistance and the external resistor, $\mathrm{R}$, and $\mathrm{C}$ is the capacitance $(80,000 \mu \mathrm{F})$. In the case where the internal power supply resistance is a nominal $50 \mathrm{ohms}, \mathrm{R}$ is 10 ohms, and $C$ is $80,000 \mu \mathrm{F}, \mathrm{TC}=4.8 \mathrm{sec}$. This means that $\mathrm{C}$ will charge to $63.2 \%$ of the applied power supply voltage in $4.8 \mathrm{sec}$, or to $95 \%$ of applied voltage in three time constants $(14.4 \mathrm{sec})$. The capacitor should be allowed to recharge for a period of at least three time constants prior to performing the next weld to insure uniformity of the welds. Should the value of the external resistor, $R$, be increased to limit the initial charging current, the TC may change also. This can be evaluated by Formula 2 and should be considered in determining how long $\mathrm{C}$ should recharge between welds.

The current to the weld is limited by the gauge of the wire and the charge on the capacitor. Normally, we employ 10-ga copper wire, which provides a current-carrying capacity of $14.8 \mathrm{~A}$. Table 1 lists the current-carrying capacity of several most commonly used wire sizes.

The welding tweezers consist essentially of two steel blades strapped to a wooden block in the form of a pair of large forceps, with replaceable copper alloy tips. The tweezers and/or tips can be purchased commercially ${ }^{1}$ if desired. One of the tips may be wedged to hold a wire against a flat surface (e.g., disk electrode). Flat tips are best for welding two wires together. Materials to be welded must be clean, and the welding tips periodically cleaned and reshaped with emory cloth.

Although the structural strength of the welds is good, if the welds are to be positioned such that they will be subject to movement or stress, a form of strain relief 
Table 1

Current-Carrying Capacity of Copper Wire Rated at 700 C.M. Per Ampere

\begin{tabular}{cccc}
$\begin{array}{c}\text { Wire } \\
\text { Size } \\
\text { AWG }\end{array}$ & $\begin{array}{c}\text { Diameter } \\
\text { in Mils }\end{array}$ & $\begin{array}{c}\text { Circular } \\
\text { Mil Area } \\
\text { (C.M.) }\end{array}$ & $\begin{array}{c}\text { Current- } \\
\text { Carrying } \\
\text { Capacity } \\
\text { (Amperes) }\end{array}$ \\
\hline 7 & 144.3 & 20820 & 29.7 \\
8 & 128.5 & 16510 & 23.6 \\
9 & 114.4 & 13090 & 18.7 \\
10 & 101.9 & 10380 & 14.8 \\
11 & 90.7 & 8234 & 11.8 \\
12 & 80.8 & 6530 & 9.33 \\
13 & 72.0 & 5178 & 7.4 \\
14 & 64.1 & 4107 & 5.87 \\
15 & 57.1 & 3257 & 4.65 \\
16 & 50.8 & 2583 & 3.69 \\
\hline
\end{tabular}

should be used to insure that the weld itself is not subject to stress.

The conductivity of a properly made weld is essentially the same as that of the uninterrupted parent material.

NOTE

1. Ewald Instrument Corporation, Box 124, Kent, Connecticut 06757.

(Received for publication March 9, 1973; accepted March 13, 1973.)

\section{Chronic implantation of a stable jugular catheter}

\section{DOUGLAS L. CHUTE}

Department of Psychology and John M. Dalton Research Center University of Missouri, Columbia, Missouri 65201

One method of intravenous injection in the rat has been via the femoral vein or tail vein. This method may be too slow for certain experimental or pharmacological purposes. Furthermore, a good deal of dexterity is required in handling the unanesthetized animal. The alternative has been the chronically indwelling catheter. Various methods have been described, varying in cost, availability of materials, time, and effectiveness (Still \& Whitcomb, 1956; Weeks \& Davis, 1964; Weeks, 1967; Steffens, 1969). Although of superior durability, they generally are more time consuming and costly. Often the animals' freedom of movement or the experimental apparatus has to be restricted to accommodate cantilever supports for tubing.

The following technique is effective (Chute \& Wright, 1973) and offers considerable savings in expense and effort.

\section{CONSTRUCTION ANDD IMPLANTATION}

The catheter itself is a 0.050 -in. (o.d.) polyethylene tube (Intramedic R) with one end beveled and the other press-fit over the shortened shank of a 20 -ga hypodermic needle. The needle is fitted with a 3-1 cork (Fig. 1).

The surgical procedure requires about $20 \mathrm{~min}$ from the onset of anesthesia. The head and throat are shaved and prepared. A longitudinal incision is made midline in the scalp, and tissue is retracted as far as the dorso-lateral flexures by gentle periosteal elevation. The skull is prepared, and a base of dental acrylic is applied. Secure anchoring of the acrylic base is essential, and is accomplished in the usual manner with skull screws or suture wire (Draper \& Venator, 1972). The catheter is filled with a 1,000-unit solution of sodium heparin (Liquamin R), and the corked needle hub is affixed to the base with additional dental acrylic. The acrylic also is sufficient to hold the tubing and needle junction in place.

Next, a longitudinal incision is made over the right external jugular. The cannula is run subcutaneously behind the right ear, and then eventually to the incision
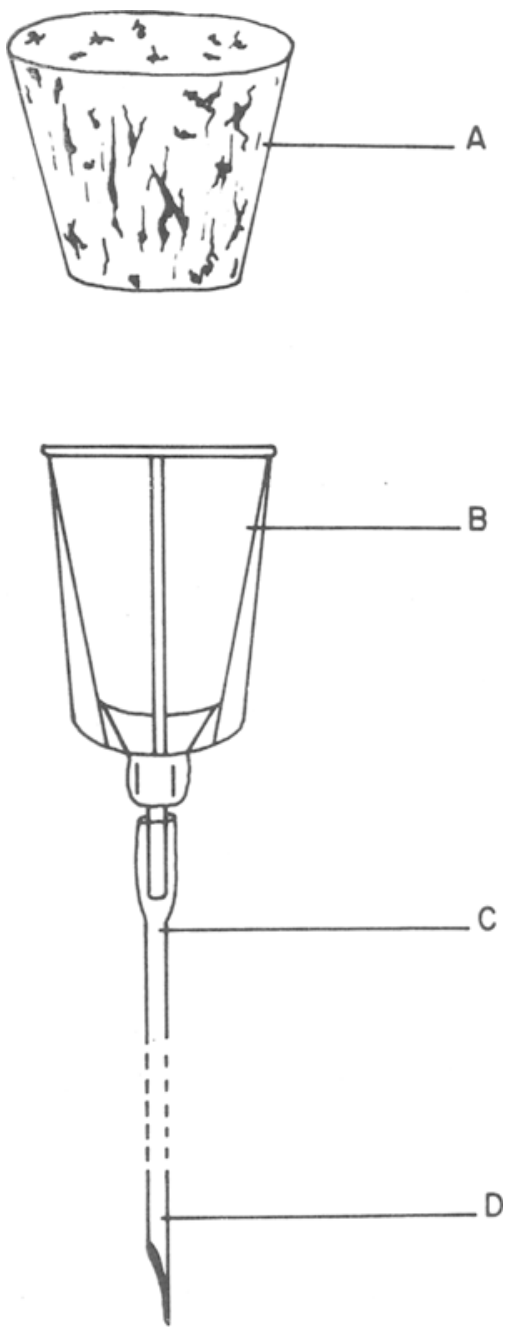

Fig. 1. Diagram of jugular catheter. Arrows indicate: (a) 3-0 cork, (b) 20-ga needle hub with shortened shank, (c) 0.050-in. o.d. polyethylene tubing, and (d) beveled end with point blunted. 